\title{
STATUS GIZI, UMUR, PEKERJAAN DENGAN PEMBERIAN ASI EKSKLUSIF PADA BAYI USIA 6-12 BULAN SAAT IBU KEMBALI BEKERJA
}

\author{
Niwayan Ayu Damayanti ${ }^{1}$, Vanda Doda ${ }^{2}$, Sefti Rompas ${ }^{3}$ \\ 1. Mahasiswa Program Studi Ilmu Keperawatan, Fakultas Kedokteran, Univeristas Sam \\ Ratulangi, Indonesia \\ 2. Pasca Sarjana, Univeristas Sam Ratulangi, Indonesia \\ 3. Program Studi Ilmu Keperawatan, Fakultas Kedokteran, Univeristas Sam Ratulangi, \\ Indonesia \\ Email: Niwayandamayanti9@gmail.com.
}

\begin{abstract}
Exclusive breastfeeding is giving ASI as early as possible after birth until the baby is 6 months old however, there were still mothers who did not exclusively breastfeed and each of them had a job. one of these studies showed that babies who were not breastfed would have a 6-10 times higher risk of dying in the first few months.This research method uses a cross sectional study design with a population of mothers who have babies aged 6-12 months. Sampling was done by non-probability sampling with pruposive sampling technique. The number of samples were 52 respondents. Data is presented in the form of Frequency Tables. Data analysis used is univariate and bivariate analysis using the chi-square analysis method. Results of research Respondents on average have a high school education. With normal nutritional status, the average mother has a age of 17-25 years, the average mother works as a private / entrepreneur. From the chi-square test results obtained $p$ value for nutritional status $\rho=0.02$ smaller than $\alpha=0.05, p$ value for age $\rho=0.03$, smaller than $\alpha=0.05$, and $p$ value for work $\rho$ $=0.03$, smaller than $\alpha=0.05$. In conclusion, the results of this study indicate that there is a significant relationship between nutritional status, age, occupation and exclusive breastfeeding in infants aged 6-12 months when mothers return to work at Wilaya Work Center at Werdhi Agung Public Health Center, Dumoga Tengah District.
\end{abstract}

\section{Keywords: Nutrition Status, Age, Employment, and Exclusive Breastfeeding}

\begin{abstract}
Abstrak: ASI Ekslusif adalah pemberian ASI sedini mungkin setelah lahir sampai bayi berumur 6 bulan namun masih didapatkan ibu yang tidak memberikan ASI secara ekslusif, dan masing-masing dari ibu tersebut memiliki pekerjaan salah satu penelitian ini menunjukan bahwa bayi yang tidak diberikan ASI akan memiliki resiko 6-10 kali lebih tinggi meninggal pada beberapa bulan pertama. Metode penelitian ini menggunakan desain penelitian cros sectional dengan populasi ibu yang mempunyai bayi usia 6-12 bulan. Pengambilan sampel dilakukan secara non probability sampling dengan teknik pruposive sampling. Jumlah sampel sebanyak 52 responden. Data disajikan dalam bentuk Frequency Table, Analisis data yang digunakan adalah analisis univariat dan bivariat dengan menggunakan metode analisis chisquare. Hasil penelitian Responden rata-rata memiliki pendidikan SMA. Dengan status gizi normal, rata-rata ibu memiliki umur 17-25 tahun, rata-rata ibu bekerja sebagai Swasta/Wirausaha. Dari hasil uji chi-square didapatkan hasil nilai p untuk status gizi $\rho=0,02$ lebih kecil dari $\alpha=0,05$, nilai $p$ untuk umur $\rho=0,03$, lebih kecil dari $\alpha=0,05$, dan nilai $p$ untuk pekerjaan $\rho=0,03$, lebih kecil dari $\alpha=0,05$. Kesimpulan, hasil penelitian ini menunjukan ada hubungan yang bermakna antara status gizi, umur, pekerjaan dengan pemberian ASI Ekslusif pada bayi usia 6-12 bulan saat ibu kembali bekerja di Wilaya Kerja Puskesmas Werdhi Agung Kecamatan Dumoga Tengah.
\end{abstract}

Kata Kunci: Status Gizi, Umur, Pekerjaaan, Dan Pemberian Asi Ekslusif 


\section{PENDAHULUAN}

Asi Susu Ibu (ASI) adalah suatu jenis makanan yang mencakupi seluruh unsur kebutuhan bayi baik fisik,psikologis social, maupun spiritual. ASI Ekslusif adalah pemberian asi sedini mungkin setelah lahir sampai bayi berumur 6 bulan tanpa pemberian makanan lain. Tindakan ini akan terus merangsang produksi ASI sehingga pengeluaran asi dapat mencukupi kebutuhan bayi dan bayi akan terhindar dari diare. ASI ekslusif atau lebih tepat pemberian asi secara ekslusif adalah bayi hanya diberi ASI saja, tanpa tambahan cairan lain seperti susu formula,jeruk,madu,air teh,air putih, dan tanpa tambahan makanan padat seperti pisang, pepaya, bubur susu, biskuit, bubur nasi.setelah 6 bulan baru mulai diberikan makanan pendamping ASI ( MPASI).

\section{Menurut World Health Organitation} (WHO) 2016, cakupan ASI eksklusif di seluruh dunia hanya sekitar $36 \%$ selama periode 2007-2014. Secara Nasional di Indonesia, cakupan bayi mendapat ASI eksklusif sebesar $61,33 \%$ telah mencapai target renstra tahun 2017 yaitu $44 \%$. (Depkes RI, 2017). Menurut survei demografi kesehatan indonesia (SDKI) 2013 menunjukan peningkatan terhadap angka pemberian ASI ekslusif, dibandingkan SDKI 2007. Pada SDKI 2007 angka pemberian ASI ekslusif itu hanya sekitar 32\%' yang di SDKI 2013 sudah meningkat menjadi $42 \%$ jadi ada peningkatan sebanyak $10 \%$. SDKI terbaru yang dilakukan tahun 2012 menunjukkan bahwa hanya 27 persen bayi umur 4-5 bulan mendapat ASI ekslusif (tanpa tambahan makanan atau minuman lain). Selain ASI $8 \%$ bayi pada umur yang sama diberi susu lain dan $8 \%$ diberi air putih. Pemberian ASI ekslusif kepada bayi berusia 4-5 bulan dalam SDKI 2012 lebih tinggi dibandingkan dengan hasil SDKI 2007 (masing-masing 27\% dan $17 \%$ ). Pada tahun 2011 jumlah bayi ada 272 yang mendapatkan asupan ASI ekslusif berjumlah 126 bayi atau 46,32\% sedangkan yang tidak mendapatkan asupan ASI ekslusif berjumlah 146 bayi atau $53,68 \%$.sulawesi utara cakupan bayi yang mendapat ASI eksklusif adalah 39,42\% atau naik dibandingkan dengan tahun 2015 yang mempunyai cakupan $33.58 \%$. (Dinkes, Sulut 2016).

Menurut hasil Riset Kesehatan Dasar (Riskesdas) tahun 2010, Masalah pemberian ASI Ekslusif disebkan oleh faktor salah satunya karena masih rendahnya tingkat pengetahuan pada ibu bekerja mengenai pentingnya ASI ekslusif, hal ini disebabkan banyak ibu yang menganggap bahwa bayinya sudah diberikan ASI ekslusif secara utuh. tetapi pada ibu bekerja bayinya diberi susu formula. Pada saat ibu bekerja juga memberikan tambahan makanan selain ASI yaitu diberi pisang dan nasi lembut karena dengan pemberian makanan tambahan kepada bayinya ibu merasa bayinya akan lebih tercukupi kebutuhan gizinya.

Survei data awal yang diambil dari Puskesmas Werdhi Agung pada bulan Maret-Mei 2019 didapati jumlah ibu yang mempunyai bayi 6-12 bulan berjumlah 60 ibu. Dari hasil observasi yang dilakukan peneliti pada $10 \mathrm{ibu}$ yang membawah bayi untuk melakukan imunisasi, di dapatkan 6 ibu memiliki pekerjaan dan 4 ibu tidak memiliki pekerjaan. Rata-rata ibu tersebut berusia 22 tahun ke atas. Status gizi yang dimiliki $10 \mathrm{ibu}$ yang membawah bayi imunisasi di puskesmas werdhi agung, 6 ibu dengan status gizi normal dan 2 ibu dengan status gizi kurus dan 2 ibu dengan status gizi gemuk, hasil status gizi tersebut peneliti dapatkan melalui rumus Indeks Masa Tubuh (IMT). Dan hasil wawancara didapatkan 7 ibu memberikan ASI Eksklusif dan 3 ibu memberikan Susu formula. Alasan ketiga ibu yang hanya memberikan Susu formula dikarenakan ibu yang sibuk bekerja dan ada juga karena masalah ASI yang tidak keluar. Di dapati status gizi dari ketiga ibu tersebut $2 \mathrm{ibu}$ memiliki status gizi kurus, yang bekerja 
sebagai ibu rumah tangga (IRT) dan sebagai PNS. 1 ibu dengan status gizi normal bekerja sebagai IRT. Menurut penelitian yang di lakukan oleh Bahriyah dkk (2017) Kecenderungan ibu-ibu tidak memberikan ASI Eksklusif dikarenakan banyaknya ibu-ibu yang bekerja. Selain itu, kecendrungan ini juga terjadi dikarenakan bagi pekerja wanita yang melahirkan, memberikan ASI Eksklusif merupakan suatu dilema, karena masa cuti terlalu singkat dibandingkan masa menyusui, sehingga mereka akan memberikan susu formula sebagai pengganti ASI Eksklusif. Menurut Widiastuti 2013 Mengatakan bahwa ASI memiliki semua unsur-unsur yang memenuhi kebutuhan bayi akan gizi selama periode sekitar 6 bulan, kecuali jika ibu mengalami keadaan gizi kurang yang berat atau gangguan kesehatan lain.

\section{METODE PENELITIAN}

Penelitian ini termasuk dalam penelitian kuantitatif dan penelitian ini menggunakan desain penelitian cross sectional. Penelitian ini dilaksanakan diwilayah kerja puskesmas Werdhi Agung Kecamatan Dumoga Tengah, pada bulan Agustus 2019. Populasi dalam penelitian ini adalah ibu yang mempunyai bayi usia 6-12 bulan yang ada di wilayah kerja puskesmas werdhi agung kecamatan dumoga tengah. Yang diambil 3 bulan terakhir dari bulan Maret-Mei 2019 yang berjumlah 60 ibu. Pengambilan sampel pada penelitian ini dilakukan secara non probability sampling dengan teknik pruposive sampling dengan rumus slovin maka didapatkan jumlah sampel 52 responden. Instrumen yang digunakan dalam penelitian ini menggunakan lembar observasi dan kuesioner. Di mana lembar observasi tentang status gizi, umur dan pekerjaan responden. Lembar obervasi tersebut berisikan data umum responden dan status gizi responden yang akan peneliti ukur menggunakan rumus IMT. Sedangkan untuk kuesioner dalam penelitian ini tentang kuesioner tentang pemberian ASI Eklsusif pada bayi usia 6-12 bulan.
Pengolahan data yang diperoleh dari hasil penelitian ini dianalisis menggunakan uji statistik melalui system komputerisasi dengan beberapa tahap yaitu editing, coding, tabulasi data (Notoatmodjo, 2010). Analisa bivariat dalam penelitian ini yaitu untuk mengetahui hubungan status gizi,umur,pekerjaan dan Pemberiaan Asi Ekslusif pada bayi 6-12 bulan saat ibu kembali bekerja di Wilayan Kerja Puskesmas Werdhi Agung Kecamatan Dumoga Tengah. Penelitian ini menggunakan uji Chi-square dengan tingkat kepercayaan 95\% $(\alpha=0,05)$. Ketentuan hubungan bermakna jika nilai $\mathrm{p}<0,05$ dan tidak bermakna jika nilai $\mathrm{p}>0,05$.

\section{Etika Penelitian}

Etika penelitian ini telah dilakukan dengan standar etika penelitian yaitu :

1. Informed consent(Lembar Persetujuan)

2. Anonimity ( tanpa nama)

3. Confidantiality ( kerahasiaan)

Penelitian ini telah diberi isin oleh puskesmas Werdhi Agung.

\section{HASIL dan PEMBAHASAN}

\section{Gambaran Umum Tempat Penelitian}

\section{a. Puskesmas Werdhi Agung}

Puskesma Werdhi Agung membeawa 1 kecamatan yaitu kecamatan dumoga. Luas wilaya dumoga tengah 34,24 $\mathrm{km}$ mencakup 10 desa yaitu: Desa Ibolian 1, desa ibolian, desa werdhi agung, desa werdhi agung selatan, desa werdhi agung timur, desa werdi agung utara, desa kinomaligan, desa kosio timur, desa kosio, dan desa kosio barat. Kecamatan dumoga tengah merupakan daerah beriklim tropia dengan curah hujan cukup tinggi antara 2000-3000 mm/tahun dan juga merupakan dataran type A. Dalam hal ini dataran bolaang monggondow bagian tengah. Transportasi di kecamatan dumoga tengah secara umum dapat ditempuh dengan sarana transportasi roda dua dan sarana 
trasnportasi roda empat karena seluruh desa yang ada sudah terbuka oleh jalan- jalan yang di bangun pemerintah atau swadaya masyarakat.

\section{Karakteristik Responden}

Tabel 1 Distribusi Responden Berdasarkan pendidikan

\begin{tabular}{ccc}
\hline Pendidikan & $\mathbf{n}$ & \% \\
\hline SMA & 31 & 59,6 \\
SMP & 7 & 13,5 \\
S1 & 14 & 26,9 \\
\hline Total & $\mathbf{5 2}$ & $\mathbf{1 0 0 \%}$
\end{tabular}

Sumber : Data Primer, 2019

Hasil penelitian menunjukan bahwa dari 52 responden sebagian besar responden berpendidikan menegah atas (SMA) berjumlah 31 responden.

Hasil penelitian ini sejalan dengan Andayani \& Eko 2013 dengan judul "Hubungan Pengetahuan Ibu Tentang ASI Eksklusif Pada Ibu Bekerja" yang menyebutkan bahwa tingkat pengetahuan dipenagaruhi oleh pendidikan. Resonden yang setuju dalam memberikan ASI Eksklusif sebagian besar memiliki tingkat pengetahuan yang tinggi. Hal ini juga sejalan dengan penelitian dari Astuti (2013) yang menyatakan bahwa ibu yang setuju dalam pemberian ASI Ekslusif sebagian besar pada ibu yang

\section{Analisis Univariat}

Table 2 Distribus Responden Berdasarkan Status Gizi

\begin{tabular}{ccc}
\hline Status Gizi & n & \% \\
\hline Kurus & 11 & 21,2 \\
Normal & 31 & 59,6 \\
Gemuk & 10 & 19,2 \\
\hline Total & $\mathbf{5 2}$ & $\mathbf{1 0 0 \%}$ \\
\hline
\end{tabular}

Sumber : Data Primer, 2019

Hasil penelitian menunjukan bahwa dari 52 responden sebagian besar status gizi ibu yang mempunyai bayi usia 6-12 bulan yaitu ibu dengan status gizi normal berjumlah 31 responden. berpendidikan tinggi. Menurut Astuti (2013) pendidikan ibu berpengaruh terhadap pemberian ASI Ekslusif dan IMD. Ibu yang berpendidikan tinggi akan lebih baik penerimaanya terhadap ASI Eksklusif serta lebih berupaya untuk mempraktekannya.

Pendidkan akan berpengaruh pada seluruh aspek kehidupan manusia baik pikiran, perasan maupun sikapnya. Semakin tinggi tingkat pendidikan seseorang semakin tinggi pula kemampuan dasar yang dimiliki seseorang, khusunya pemberian ASI Ekslusif. Tingkat pendidikan dapat mendasari sikap ibu dalam menyerap dan mengubah sistem informasi tentang ASI. 
Rembet, dkk, (2017) menyebutkan bahwa Status gizi ibu menjadi hal yang penting untuk dipersiapkan sebelum masa kehamilan karena IMT pra hamil normal akan lebih mampu mencapai kenaikan berat badan hamil sesuai rekomendasi, sehingga ibu memiliki cadangan lemak yang cukup untuk menyusui saat post partum, karena tidak tepat apabila seorang ibu dapat memberikan ASI Ekslusif kepada bayinya, namun mengorbankan status gizi bayinya ataupun status gizi ibu itu sendiri ataupun mengorbankan status gizi keduannya, karena apabila ibu memberikan ASI Ekslusif selama 6 bulan dengan status gizi yang tidak baik, akan berdampak pada status gizi yang buruk pada bayi ataupun pada ibu. Menurut Alam, dkk (2003) juga menyebutkan bahwa dinegara berkembang banyak ibu yang memasuki masa laktasi dengan cadangan lemak yang kurang sehingga ibu beresiko tidak mampu memproduksi ASI yang cukup. Oleh karena itu, ibu tidak bisa memberika ASI Ekslusif pada bayi selama 6 bulan.

Tabel 3 Distribusi Responden Berdasarkan Umur

\begin{tabular}{ccc}
\hline Umur & $\mathbf{n}$ & \% \\
\hline 17- 25 Tahun & 29 & 55,8 \\
$26-35$ Tahun & 23 & 44,2 \\
\hline Total & $\mathbf{5 2}$ & $\mathbf{1 0 0}$ \\
\hline
\end{tabular}

\section{Sumber : data primer, 2019}

Hasil penelitian ini menunjukan dari 52 responden sebagian responden berumur 17-25 tahun berjumlah 29 responden.

Hal ini menunjukan sebagian besar umur responden adalah umur masa produktif, hal ini sesuai dengan Soetjidingsih (2004) dimana umur ibu di masa produktif yaitu

Tabel 4 Distribusi Responden Berdasarkan Pekerjaan

\begin{tabular}{ccc}
\hline Pekerjaan & n & \% \\
\hline PNS & 15 & 28,8 \\
Swata/Wirausaha & 27 & 51,9 \\
Tani & 10 & 19,2 \\
\hline Total & $\mathbf{5 2}$ & $\mathbf{1 0 0 \%}$
\end{tabular}

Sumber : data primer, 2019

Hasil penelitian menunjukan bahwa dari 52 responden terdapat ibu yang bekerja sebagai PNS berjumlah 15 responden, dimana paling banyak ibu memberikan ASI Eksklusif berjumlah 11 responden $(73,3 \%)$. Ibu yang bekerja sebagai Swasta/Wirausaha berjumlah 27 responden. pada umur >20-35 tahun. Melihat umur tersebut dapat dinyatakan bahwa sebagian ibu melahirkan pada usia mudah. Hal ini akan mempengaruhi pengetahuan maupun perilaku sehari-hari termasuk pengetahuan dan perilaku tentang pemberian ASI Eksklusif pada bayi. 
umumnya ibu yang bekerja waktunya tersita oleh pekerjaannya yang pada akhirnya dapat mempengaruhi kehidupan keluarga salah satunya pemberian ASI eksklusif Oleh karena itu sangat penting untuk memberikan pengetahuan pada ibu yang bekerja tentang manfaat ASI dan menyusui, memerah ASI, cara menyimpan dan memberikan ASI, perah, bagaimana melakukan manajemen laktasi sejak hamil sehingga para ibu bekerja tetap dapat memberikan ASI eksklusif serta mengusahakan adanya peraturan dari pemerintah daerah agar setiap pemilik tempat kerja memberikan dukungan untuk keberhasilan pemberian ASI eksklusif. (Shaliha, 2019).

Tabel 5 Distribusi Responden Berdasarkan Pemberiaan ASI Ekslusif

\begin{tabular}{ccc}
\hline Pemberian ASI & n & \% \\
\hline Ya & 28 & 53,8 \\
Tidak & 24 & 46,2 \\
\hline Total & $\mathbf{5 2}$ & $\mathbf{1 0 0 \%}$
\end{tabular}

Sumber : data primer, 2019

Dari hasil penelitian diperoleh bahwa ibu yang memberikan ASI Eksklusif yang mempunyai bayi berusia 6-12 bulan berjumlah $28(53,8 \%)$ responden..

Hasil penelitian ini sejalan dengan penelitian dari Bahriyah \& Jaelani (2017) yang menebutkan bahwa memberikan ASI Ekslusif kepada bayi sangatlah penting untuk tumbuh kembang bayi, namun masi banyak juga ibu-ibu dengan berbagai alasan tidak memberikan ASI Eklsusif pada bayinya, sehingga cakupan pemberian ASI Ekslusif tidak tercapai. ASI
Eksklusif mencakup manfaatnya bagi bayi maupun bagi sang ibu maupun bagi keluarga secara umum. Jika dilakukan dengan baik, maka ASI Ekslusif merupakan nutrien utama bagi bayi, sedangkan bagi ibu menyusui dapat mencegah beberapa penyakit ibu serta aspej psikologis, selain itu pemberian ASI Ekslusif berdampak pada aspek ekonomi, dimana kebutuhan ASI cukup untuk memberikan nutrisi kepada bayi dengan tidak diperlukannya susu formula yang berarti akan memperkecil pengeluaran keluarga (Setiyowat \& Husada, 2010).

\section{Analisis Bivariat}

Tabel 4 Hubungan status gizi dengan pemberian ASI Eksklusif

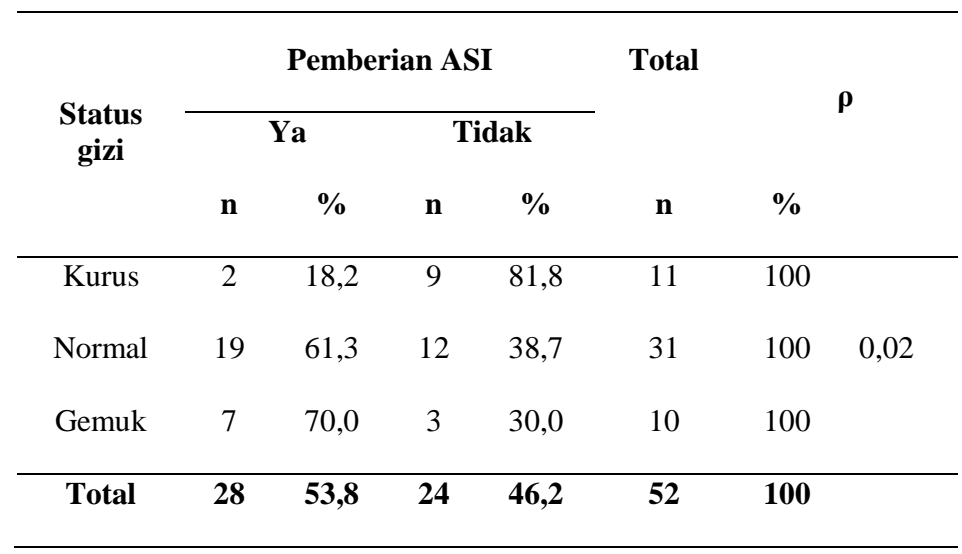

Sumber : Data Primer, 2019 
Hasil uji hipotesa dari status gizi dengan pemberian ASI Ekslusif pada bayi usia 612 bulan saat ibu kembali bekerja menggunakan uji Chi-square pada tingkat kemaknaan 95\% $(\alpha=0,05)$, menunjukan adanya hubungan yang signifikan antara status gizi dengan pemberian ASI Eksklusif pada bayai usia 6-12 bulan saat ibu kembali bekerja di Puskesmas Werdhi Agung Kecamatan Dumoga Tengah. Dimana nilai $\mathrm{p}$-value $=0,025$ lebih kecil dari $\alpha=0,05$.

Hasil penelitian ini sesuai dengan peneletian sebelumnya Wahyuni (2015) bahwa terdapat hubungan yang signifikan antara Hubungan status gizi ibu dengan pemberian ASI Eksklusif di Puskesmas Umbulharjo I Yogyakarta. Didaptkan pvalue $0,014<$ dari $\alpha=0,05$ artinya ada hubungan antara status gizi dengan pemberian ASI Eksklusif.

Hasil penelitian yang peneliti dapatkan menggunakan lembar observasi status gizi, peneliti menggukur status gizi responden menggunakan rumus IMT, dari 52 responden, ibu dengan bayi usia 6-12 bulan sebagian besar ibu memiliki status gizi normal sebanyak 31 responden dan ibu dengan status gizi kurus berjumlah 11 responden, sedangkan ibu dengan status gizi gemuk berjumlah 10 responden. Ibu dengan status gizi normal sebagian besar setuju untuk memberikan ASI Eklsklusif pada bayi berjumlah 19 responden dan 12 rsponden, dan ibu dengan status gizi kurus yang tidak setuju memberikan ASI ekslkusif berjumlah 9 responden dan yang setuju hanya 2 responden, sedangkan ibu dengan status gizi gemuk yang setuju untuk memberikan ASI Eklusif berjumlag 7 responden dan yang tidak setuju berjumlah 3 responden.

Dari hasil wawancara yang peneliti dapatkan beberapa ibu yang tidak setuju untuk memberikan ASI Ekslusif karena ASI ibu sedikit yang keluar yang membuat bayi tidak puas jika hanya diberikan ASI saja, ibu juga sering merasa nyeri di puting susu. Sedangka untuk ibu yang setuju untuk memberika ASI Eklusif karena menurut ibu ASI sangat penting Unutuk tumbuh kembang bayi. Dapat disimpulakn bahwa ibu yang paling banyak tidak setuju untuk memberikan ASI Ekslusif terdapata pada ibu yang berstatus gizi kurus. Menurut Hariyani (2010) jika asupan energi ibu menyusui yang kurang dari 1500 kalori per hari dapat menyebabkan terjadinya penurunan total lemak serta terjadi perubahan pola asam lemak.

Tabel 5 Hubungan Umur dengan pemberian ASI Eksklusif

\begin{tabular}{|c|c|c|c|c|c|c|c|}
\hline \multirow[t]{3}{*}{ Umur } & \multicolumn{4}{|c|}{ Pemberian ASI } & \multicolumn{2}{|c|}{ Total } & \multirow[t]{3}{*}{$\mathbf{P}$} \\
\hline & \multicolumn{2}{|c|}{$\mathbf{Y a}$} & \multicolumn{2}{|c|}{ Tidak } & \multirow[b]{2}{*}{$\mathbf{n}$} & \multirow[b]{2}{*}{$\%$} & \\
\hline & $\mathbf{n}$ & $\%$ & $\mathbf{n}$ & $\%$ & & & \\
\hline 17-25 Tahun & 20 & 69,0 & 9 & 31,0 & 29 & 100 & \multirow{2}{*}{0,03} \\
\hline 26-35 Tahun & 8 & 34,8 & 15 & 65,2 & 23 & 100 & \\
\hline Total & 28 & 53,8 & 24 & 46,2 & 52 & 100 & \\
\hline
\end{tabular}

Sumber : data primer, 2019

Hasil uji hipotesa dari umur dengan pemberian ASI Eksklusif pada bayi usia 612 bulan saat ibu kembali bekerja menggunaka uji Chi-square pada tingkat kemaknaan 95\%, menunjukan terdapat hubungan yang signifikan antara umur dengan pemberian ASI Eksklusif pada bayi usia 6-12 bulan saat ibu kembali bekerja di Puskesmas Werdhi Agung Kecamatan Dumoga Tengah. Dimana nilai $\mathrm{p}$-value $=$ 0,03 lebih kecil dari $\alpha=0,05$. Hasil penelitian ini sejalan dengan Rahmawati 
(2010) dengan judul "Faktor-faktor yang memepenagaruhi pemberian ASI Ekslusif pada ibu Menyusui" yang menyebutkan bahwa ada hubungan yang signifikan antara umur dengan pemberian ASI Ekslusif.

Hasil penelitian yang peneliti dapatkan ibu yang berumur 17-25 tahun berjumlah 29 responden dan yang setuju untuk memberikan ASI Eksklusif berjumlah 20 responden dan yang tidak setuju berjumlah 9 responden. Sedangna ibu dengan umur 26-35 tahun berjumlah 23 resonden. Ibu yang setuju untuk memberikan ASI Eksklusif berjumlah 8 responden dan yang tidak setuju bejumlah 15 responden. Dapat di lihat bahwa sebagian besar yang tidak setuju untuk membeikan ASI Eksklusif terdapat pada kalangan ibu yang berusia 26-35 tahun. Alasan ibu yang tidak setuju untuk memberikan ASI Eklsusif karena ibu mengatakan tidak mempunyai waktu yang cukup untuk meberikan ASI kepada bayi, dan ibu juga mengatakan ASI yang keluar sudah tidak terlalu banyak sehingga membuat bayi rewel karena tidak puas dengan ASI yang di berikan sehingga ibu menambahkan susu formula. Dara hasil kuesioner pemberian ASI Ekslusif yang peneliti dapatan kebanyakn ibu yang mempunyai bayi usia 6-12 saat ibu kembali bekerja, ibu yang berumur 26-35 tahun tidak memahami tentang ASI Eksklusif ibu. Dan sebagian besar ibu yang setuju untuk memberikan ASI Ekslusif di kalangan ibu yang berusia 17-25 tahun.

Menurut Shaliha, dkk (2019) tidak semua wanita mempunyai kemampuan yang sama dalam menyusui. Pada umumnya wanita lebih muda, kemampuan menyusui lebih baik daripada wanita yang lebih tua. Salah satu faktor penyebabnya adalah adanya perkembangan kelenjar yang matang pada pubertas dan fungsinya yang berubah sesudah melahirkan bayi. Untuk itu perlu persiapan yang lebih bagi ibu yang berumur 35 tahun keatas dalam pemberian ASI eksklusif seperti persiapan diri dalam hal memperbanyak ASI sehingga ASI ibu lancar dan cukup untuk dikonsumsi bayi seperti mengkonsumsi makanan bergizi, istirahat yang cukup, meluangkan waktu yang cukup agar bayi dapat disusui sesering mungkin serta dalam meningkatkan pencapaian pemberian ASI eksklusif diberikan batasan usia melahirkan ibu sampai 35 tahun yang terkait batasan usia yang baik dalam menyusui.

Tabel 6 Hubungan Pekerjaan dengan pemberian ASI Eksklusif

\begin{tabular}{|c|c|c|c|c|c|c|c|}
\hline \multirow[t]{3}{*}{ Pekerjaan } & \multicolumn{4}{|c|}{ Pemberian ASI } & \multicolumn{2}{|c|}{ Total } & \multirow[t]{3}{*}{$\mathbf{P}$} \\
\hline & \multicolumn{2}{|c|}{ Ya } & \multicolumn{2}{|c|}{ Tidak } & \multirow[b]{2}{*}{$\mathbf{n}$} & \multirow[b]{2}{*}{$\%$} & \\
\hline & $\mathbf{n}$ & $\%$ & $\mathbf{n}$ & $\%$ & & & \\
\hline PNS & 11 & 73.3 & 4 & 26,7 & 15 & 100 & \\
\hline Swasta/Wirausaha & 15 & 55,6 & 12 & 44,4 & 27 & 100 & 0,03 \\
\hline Tani & 2 & 20,0 & 8 & 80,0 & 10 & 100 & \\
\hline Total & 28 & 53,8 & 24 & 46,2 & 52 & 100 & \\
\hline
\end{tabular}

Hasil uji hipotesa dari dukungan pekerjaan dengan pemberian pemberian ASI Ekslusif pada bayi usia 6-12 bulan saat ibu kembali bekerja menggunakan uji Chi-square pada tingkat kemaknaan 95\% $(\alpha=0,05)$, menunjukan adanya hubungan yang signifikan antara pekerjaan dengan pemberian ASI Eklsusif pada bayi usia 612 bulan saat ibu kembali bekerja di
Pusksemas Werdhi Agung Kecamatan Dumoga Tengah. Dimana nilai $\mathrm{p}$-value $=$ 0,03 lebih kecil dari $\alpha=0,05$. Hasil penelitian ini sejalan dengan Dahlan dengan judul "Hubungan status pekerjaan dengan pemberian ASI Eksklusif di Kelurahan Palebon Kecamatan Pedurangan Kota Semarang" yang menyatakan bahwa ada hubungan yang signifikan antara 
pekerjaan dengan pemberian ASI Eksklusif.

Hasil penelitian menunjukan sebagian besar ibu mendukug untuk bekerja berjumlah 31 responden, dan pada ibu yang mendukung untuk bekerja terdapat 12 responden yang setuju untuk memberikan ASI Eklsusif sedangkan ibu yang tida setuju untuk memberikan ASI Eklsusuif berjumlah 19 responden. Dikategorikan mendukung dikarenakan ibu memilih sangat setuju jika suami mengambil peran penting dalam keberhasilan menyusui, ibu juga setuju meski ibu bekerja ibu harus menyusui sesering mungkin jika ibu berada dirumah, ibu juga setuju jika suami membantu pekerjaan rumah tangga atau mengurus bayi. Ibu juga sangat setuju jika ditempat kerja menyediakan ruangan atau pojok laktasi. Pada responden yang tidak mendukung untuk bekerja berjumlah 21 responden. Dan pada ibu yang tidak memdukung untuk bekerja terdapat 16 responden yang setuju untuk memberikan ASI Eksklusif, sedangkan yang tidak setuju untuk meberikan ASI Eksklusif berjumlah 5 Responden. Dikategorikan tidak mendukan dikarenakan ibu yang bekerja tidak memberikan ASI sesering mungkin ketika berada dirumah, ibu juga bekrja juga setuju jika tidak memberikan ASI sesering mungkin selama 6 bulan, ditempat kerja ibu juga tidak tersedia untuk ruangan atau pojok laktasi.

Hasil tersebut menunjukan bahwa ibu yang mendukung untuk bekerja lebih banyak tidak setuju untuk memberikan ASI Eksklusif. Sedangkan untuk ibu yang tidak mendukung untuk bekerja lebih sedikit yang tidak setuju untuk meberikan ASI Eksklusif. Hasil yang peneliti dapatkan menggunakan kuesioner ada beberapa ibu yang tidak setuju untuk menyusui sesering mungkin bila berada di rumah menurut ibu sudah terbiasa tidak menyusui bayi sepenuhnya maka ibu juga sering menambahkan susu formula kepada bayinya. Ada juga beberapa ibu mengatakan tidak mempunyai tempat atau rungan untuk laktasi, dan menurut ibu ditempat kerja tidak diberikan waktu yang fleksibel untuk memerah ASI atau menyusui. Menurut Bahriyah (2017) menyatakan bahwa Kecenderungan ibu-ibu tidak memberikan ASI Eksklusif dikarenakan banyaknya ibu-ibu yang bekerja. Selain itu, kecendrungan ini juga terjadi dikarenakan bagi pekerja wanita yang melahirkan, memberikan ASI Eksklusif merupakan suatu dilema, karena masa cuti terlalu singkat dibandingkan masa menyusui, sehingga mereka akan memberikan susu formula sebagai pengganti ASI Eksklusif.

Hasil penelitian yang di lakukan oleh Lestari, dkk, (2013) menunjikan bahwa ibu yang tidak melakukakn pekerjaan di luar rumah akan memiliki banyak waktu dan kesempatan untuk menyusui bayinya dibandingkan dengan ibu yang bekerja di luar rumah, sebenarnya ibu yang bekerja masi dapat memberikan ASI Eksklusif kepada bayinya dengan memerah ASI baik menggunakan alat/pompa aupun tangan, kemudian disimpan dan dapat diberikan kepada bayi selama ibu bekerja. penelitian ini sejalan dengan Sriningsih (2011) yang menyatakan bahwa ibu-ibu yang bekerja sebagian besar waktunya tersita untuk pekerjaan yang akhirnya waktu menyusui akan berkurang. Ibu kembali bekerja penuh sebelum bayi berusia enam bulan menyebabkan pemberian ASI eksklusif ini tidak berjalan sebagaimana seharusnya, belum lagi ditambah kondisi fisik dan mental yag lelah karena harus bekerja sepanjang hari dan ditambah diet yang kurang memadai jelas akan berakibat pada kelancaran produksi ASI. Adanya peraturan cuti yang hanya berlangsung selama 3 bulan membuat banyak ibu harus mempersiapan bayinya dengan makanan pendamping ASI sebelum masa cutinya habis, sehingga pemberian ASI eksklusif menjadi tidak berhasil. (Astuti, 2013). 


\section{SIMPULAN}

Diharapkan adanya usaha untuk memantapkan pelaksanaan ASI Ekslusif bagi pekerja wanita melalui pembinaan dan dukungan penuh pihak pengusaha. Dengan menyediakan saran ruang memerah ASI, menyediakan perlengkapan untuk memerah dan menyimpan ASI. Diharapkan adanya usaha untuk mampu menciptakan kondisi yang dapat mendukung ibu-ibu untuk menyusui secara eklusif, dengan melakukan komunikasi persuasif saat melakukan pelayanan kesehatan. Untuk penelitian selanjutnya diharapkan untuk meneliti faktor-faktor lain yang mempengaruhi pemberian ASI Ekslusif yang lebih luas seperti faktor sosial budaya, dan faktor fisik ibu.

\section{DAFTAR PUSTAKA}

Andayani, R. S. \& Eko, M. (2013). Hubungan Pengetahuan Ibu Tentang ASI Ekslusif dengan praktek pemberian ASI Ekslusif pada ibu bekerja di Kelurahan Ngempon Kecamatan Bergas Kabupaten Semarang. Akademi Kebidanan Ngudi Waluyo Ungaran.

Astuti, I. (2013). Determinan pemberian ASI Eklsusif pada ibu menyusui. Jurnal Health Quality.

Bahriyah, F. Putri, M. \& Jaelani, A. K., (2017). Hubungan pekerjaan ibu terhadap pemberian ASI Eksklusif pada bayi di wilaya kerja uskesas Sipayung. Jurnal Edurance: Kajian ilmiah problema kesehatan.

Depkes RI. 2017.cakupan ASI eksklusif. Jakarta Depkes RI. Diakses pada Juni 2019: http//www.depkes.com.id.

Dinkes Sulut, 2016. Cakupan bayi mendapatkan Asi eksklusif. Manado : Dinkes Sulut.

Lestari, D., Zuraida, R.,\& Larasati, T.A.(2013). Hubungan Tingkat pengetahuan ibu tentang air susu ibu dan pekerjaan ibu dengn pemberiaan ASI Ekslusif di Kelurahan Fajar Bulan.Jurnal majority,2(4).

Rembet, S. R. Mayulu, N. \& Ratag, B. T. (2017). Hubungan status gizi dengan pemberian ASI Eksklusif di kota Manado. KESMAS.

Rahmawati, M. D. (2010). Faktor-Faktor Yang Mmempengaruhi Pemberian ASI Ekslusif Pada Ibu Menyusui Di Kelurahan Pedalangan Kecamatan Banyumanik Kota Semarang. Jurnal Kesehatan Kusuma Husada.

Sriningsih, I. (2011). Faktor demografi, pengetahuan ibu tentang air susu ibu dan pemberian ASI Eksklusif. KEMAS: Jurnal Kesehatan Masyarakat.

Shaliha, A. M. Purwanti, S. K. M., \& Izzatu Arifah, S. K. M. (2019). Hubungan karakteristik ibu, pengetahuan, dukungan suami dan dukungan keluarga terhadap praktek pemberian ASI Eksklusif di wilaya kerja Puskesmas Purwodadi 1 Kabupaten Grobogan. Doctoral dissertation, Universitas Muhamadiyah Surakarta.

Setiyowati, W. \& Husada, R. K. A., (2010). Hubungan pengetahuan tentang ASI Ekslusif pada ibu bekerja dengan pemberian ASI Ekslusif. Jurnal Kebidanan.

Soetjidingsih. (2004). Tumbuh Kembang Remaja dan Permasalahannya. Jakrta: PTRhineka Cipta.

WHO. World Health Organitation, (2016)

Wahyuni, T, \& Suratini, S.(2015). Hubungan status Gizi ibu dengan pemberian ASI Ekslusif dipuskesmas umbulharjo I yogyakarta tahun 2015 (Doctoral dissertation, STIKES'Aisyiyah Yogyakarta). 